\title{
ELOGIO DE LO POÉTICO
}

Sergio Espinoza Proa

Universidad Autónoma de Zacatecas

Recibido: 02 - diciembre - 2015, aprobado 17 - diciembre - 2015

\section{Resumen}

Elogio a lo poético, es un estudio filosófico, epistemológico, ético y estético de la poesía. El autor, Sergio Espinosa Proa, lo leyó por primera vez en una Conferencia Magistral que tuvo lugar en el Encuentro Internacional de Poesía 2015 organizado por la Universidad Autónoma de Zacatecas, encuentro al que tuve el honor de asistir en calidad de invitado. Como Director de ANALES solicité este ensayo a Sergio Espinosa Proa y lo presento como una exclusividad de nuestra publicación.

Palabras clave: filosofía, poesía, lector, autor, literatura.

\section{Summary}

Commend the poetic, it is a philosophical, epistemological, ethical and aesthetic study of poetry. The author, Sergio Espinosa Proa, read it for the first time in a keynote lecture that was held at the International Poetry Meeting 2015, organized by the Autonomous University of Zacatecas, the very encounter I had the honor of attending as a guest. As Director of Annals I requested this essay to Sergio Espinosa Proa, and I offer it as an exclusive of our publication.

Keywords: philosophy, poetry, reader, author, literature. 
No estoy muy seguro de que leer mucho sea bueno, ni siquiera de que leer, en general, lo sea. No estoy pensando, por supuesto, en el mal que le hacen a la vista (que es considerable). Pienso en un mal de tipo metafísico; leer provoca cierta miopía o cierto astigmatismo morales. Hay una experiencia bastante violenta, una suerte de posesión, una violación sutil pero efectiva que perpetra no sólo el autor, sino todo un enjambre de entes y agentes sobre el lector, incluso —o más— si no se trata de un lector desprevenido.

Para escribir estas líneas, que existen porque mi amigo José de Jesús Sampedro tuvo la amabilidad de invitarme a este acto, gesto que agradezco sinceramente, me he visto en la necesidad de zambullirme en un marasmo de libros, revistas, plaquettes y blogs de los que dudo poder extraer algo que no sean nociones prefabricadas a propósito de un asunto tan noble, difícil y delicado como la poesía. ¿No habría sido mejor improvisar un elogio, que a duras penas requeriría la inversión de tiempo y esfuerzo en la lectura y asimilación de decenas o quizá centenas de páginas? Sin duda; habría sido mejor. Pero, ¿mejor para quién? ¿Para mí, que provisionalmente detento el "uso de la palabra", como abusivamente se dice, o para ustedes, que como mínimo tienen derecho de no aburrirse o, peor, enfadarse con las cosas que les venga a decir alguien que desde su más tierna infancia, o desde su más inestable adolescencia, decidió — como quien decide no tener hijos- nunca escribir eso que de algún modo poco o muy justificadamente llamamos "poesía"?

Puesto, sin proponérmelo, en este tono cuasi-íntimo, confesaré entre guiones que la decisión de no escribir poesía se parece mucho a la decisión de no entender un millón de cosas de esta vida, entre las cuales las matemáticas, la economía, la lógica, la política, la psicopedagogía, la jurisprudencia, la lingüística y la contabilidad se me presentaron tarde o temprano como materias literalmente intratables. Se parece, pero la decisión de no escribir poesía no procede del disgusto sino de su opuesto; la poesía es demasiado, como dicen que dijo el doctor Sigmund Freud cuando le preguntaron qué opinaba de la filosofía del señor Friedrich Nietzsche.

En todo caso, no me queda tan claro qué y para quién sería “mejor", el hecho es que he optado por una vía intermedia.

Conozco, por exigencias profesionales (pero también por pura y santa neurosis), dos "Elogios" espléndidos, uno a la antropología - el discurso de Claude Lévi-Strauss - y otro a la filosofía —el de Maurice Merleau-Ponty—, ambos leídos, si no me equivoco, con ocasión de su ingreso al College de France. No sé si por ser respectivamente un antropólogo y un filósofo lo tenían o lo tuvieron más fácil que yo, que, según he dicho, no soy poeta (ni, en rigor, "literato"); sé, al menos, que no lo soy, aunque no pueda tampoco asegurar qué es, exactamente, es decir, con independencia de lo que se anuncie en mi cédula profesional, que por cierto anda extraviada, aquello que soy. Dejémoslo en cierta propicia ambigüedad: lo que me gusta creer que soy es un lector, un lector empedernido, un lector impenitente (y demasiado a menudo infiel), con todo lo vicioso o mórbido que estos calificativos implican o sugieren. ¿Qué clase de elogio a la poesía podría corresponder a una 
persona tan poco profesionalmente calificada para ello? ¿Bastará concebirse a sí mismo — qué feo se oye-como un poetómano? Parece argumentable que hay algo más que una manía, aunque lo poético, como la música, son patologías que se contraen un día y sólo empeoran con el tiempo.

Melomanía y poetomanía son enfermedades, sin embargo, sumamente selectivas. Mientras escribo esto, sentado frente a mi laptop, escucho en internet —en Youtube - una selección de música que, milagrosamente, es decir, sospechosamente, se halla exenta de anuncios comerciales, de "espacios publicitarios". A los anunciantes, tan aplicados, tan eficientes, tan despiertos, les ha parecido, con excelentes pero oscuras razones, que la selección que en este momento he efectuado resulta irrisoria para una multitud. Para mí, en concreto. ¿Para qué tomarse - o provocar - la molestia de insertar un anuncio comercial o, peor, político, al comienzo de piezas que, en el momento en que escribo, sólo habrán de escuchar menos de cien mil personas en todo el planeta? (Qué digo cien mil, hay un compositor que tiene 321 visitas totales desde que se subió el video, en 2009). Es una bendición y una enorme ventaja tener gustos tan selectos o mafufos (es casi lo mismo), pues Johannes Hieronymus (o Giovanni Girolamo) Kapsberger, Robert de Visée, John Dowland, Melchor Nieuslider, Alessandro Piccinini, Silvius Leopold Weiss y Jacques de Saint Luc — - y hay peores — no tienen los suficientes fans como para ofender a los escasos que sí lo somos con anuncios de vaselinas, gelatinas, crinolinas y naftalinas (y eso, cuando las nenas se ponen finas).

No es una ventaja despreciable. Y es, por lo demás, sumamente instructiva. Esto de vivir en la "sociedad transparente" o en la "sociedad del conocimiento" —rótulos tan pedantes como engañosos — rinde sus enseñanzas. Por ejemplo, advertimos bastante rápido que "la música" no tiene nada qué ver con la música (escrito ahora sin comillas pero en cursivas). Tampoco "la filosofía", o "la literatura", o "el pensamiento". En nuestros días, y desde hace bastante, y viene a ser una magnífica definición del presente, prácticamente nada es lo que es. Tampoco teóricamente, la verdad. Da la impresión de que lo que realmente es se revela escondiéndose de todo aquello que se ha dado, se da y se dará por "real". Es decir, Miley Cyrus, o Justin Bieber, o Maná, ¿de verdad se venden como música? ¿Kenny G? ¿Hay pensamiento en Richard Bach o misticismo en Lobsang Rampa? Sí, por más triste que se oiga: sí, así se venden o se vendieron (y más que bien). Sin hablar, para no engordarles el caldo, de los actuales. Un resultado colateral de esta catástrofe en proceso es que la verdadera música —o la verdadera poesía, o el verdadero pensamiento - coinciden exactamente con su insignificancia, su marginalidad, su imperceptibilidad, su impopularidad, su discreción. Su silencio.

Este último rasgo — su silencio_ — es algo de lo que me puedo servir en adelante para intentar justificar un poco esto de que - ante cordilleras y océanos de basura- hay "verdadera" música o poesía, o pensamiento "de verdad". No es nada fácil, y el primer riesgo — que hay muchos — es, de nuevo, naturalmente, la pedantería. El primero, no el único. Por cierto, y como estupendo ejemplo, en la revista electrónica Círculo de poesía (de diciembre de 2011), Mario Bojórquez, después de editar para Joaquín Mortiz su correspondiente contraparte, se ha tomado el trabajo de reunir Los 100 peores poemas mexicanos — y está muy claro que se queda 
corto. No voy a citar ninguno, búsquenlos ustedes por su cuenta para su mayor solaz y esparcimiento. Los hay tan inverosímiles e "infamantes" (dice Mario) que no requieren del menor comentario, pero uno, legítimamente, se pregunta, junto a cualquiera, a propósito de los criterios empleados por el poeta para decidir su inclusión en lista tan ominosa. Tampoco abundaré sobre la —amistosa pero siempre tensa- discusión entre Evodio Escalante y Mario Bojórquez al final de los primeros cincuenta "peores" poemas. La cuestión es, precisamente, que no se sabe nunca, o no siempre, desde dónde una persona, o, mejor, un lector, agudo u obtuso, neófito o erudito, sonambúlico o alerta, solemne o sarcástico, mamón o buenpedo, decide que lo que se le vende como un poema - o un pensamientolo es o no lo es.

¿Hay criterios? No hay duda de ello. Sólo que andan como emboscados. En los comentarios que pueden leerse al final de esta lista, pocos y escuetos, y la mayoría escasamente pretenciosos o académicos, hay varias "propuestas" que - aglutinadas en una sola palabra- podemos discutir brevemente. Son, en una enumeración no exhaustiva, el bumor, lo sagrado, la genialidad, el talento, el ingenio, la eficacia, la disfrutabilidad, la expresividad, el ritmo, la emotividad, la honestidad... Es seguro que me falten algunos, pero no importa. Los criterios del maligno compilador se aclaran (o pueden hallarse) desde el principio; son, según leo, dos: el reconocimiento, primero, y el extrañamiento, después. Reconocimiento de un fondo cultural, por un lado, y distanciamiento de él, por el otro. ¿La poesía es crítica o no será? Lo esencial, para un poeta que lee poesía, y es su baremo de cabecera, su varita de agua o radiestesia, es el logro, la adquisición de un estilo propio. Con estos criterios, el que personalmente nos guste o nos haga vomitar un poema (o un poeta) viene a ser lo de menos. Hay que ceder cuando menos a una promesa de objetividad, o de no-sólo-visceralidad en nuestros juicios. El "ejercicio" de Bojórquez es instructivo, divertido y, como él mismo dice, "necesario", pero, según ahora puedo percatarme, sólo ha servido para exhibir cierto estado de miseria y postración - acompañado de su consabida soberbia y vacuidad - en los poetas mexicanos que han sido, con justicia o no, "reconocidos" por la institución (por el Estado o por la Universidad). Una rebanada bastante temblorosa — "histérica", dice Mario- de la cultura.

Pero muy aleccionadora. Si los jueces que en cada caso deciden qué es premiable y publicable y qué no están calificados para ello o si sólo aplican raseros inconscientes, flojos, tuertos o prefabricados — cuando no, horror, corporativizados- no es nada que a la poesía, hablando con franqueza, le importe de verdad. Si es poesía, se abre paso. Tal sería mi criterio, que de criterio tiene, según diré, realmente poco. Porque la poesía, mal que les pese a sus beneficiarios o perjudiciarios, una vez nacida, y más o menos libre de mucosas y escamas, de sangre y heces, o retozando en ellas, es completamente autónoma y, principalmente, indiferente a aquellos. Incluso me atrevería a decir que el poema es hostil a todo el mundo, y por principio de cuentas a su presunto autor (con o sin beca, con o sin premio).

Difícil eludir la arbitrariedad, no únicamente en los gustos, para los que es inherente, sino en los criterios, que presumen de sensatos. ¿Hölderlin escribía pensando en hacerse de un estilo propio? Patentemente no, porque se sabe que lo único que le atormentaba — le afligía tanto como le hacía feliz, y que al fin termi- 
nó volviéndolo loco — era que lo sagrado —ojo: no lo divino — fuera su palabra. No "decir lo sagrado", sino, después de ver lo que vio (Und was ich sab), que lo sagrado fuera su palabra (das Heilige sei mein Wort). Y eso, como para qué. Sin para qué, como la rosa de Angelus Silesius. Tendríamos que admitir que este "sin por qué" es la fórmula que expresa o establece la mayor exigencia, no la pérdida o desguance de todas. El sin por qué dice exactamente lo contrario de la arbitrariedad, que es en lo que por regla general se resbala cuando uno sólo o preferentemente anda en busca de un "estilo propio". No negaré que ya es algo, o mucho, y más en nuestros tiempos de indigencia total, y no sólo en nuestro país, pero, ¿ ‘irve de criterio para separar la paja del grano? No, porque puede ser que mi estilo sea quedarme con la paja, sólo la paja y nada más que la paja. Y no es albur, o un poco. La poesía no es como en el chiste mexicano de "tú que eres poeta y en el aire las compones...".

Diríase que la poesía es exactamente el reverso en fuga de ese dicho cuya vulgaridad es más bien acojonante (de estar en Castilla). El poema, con perdón, no dice lo que el poeta quiere - el poeta es aquello contra lo cual choca el poema-, sino lo que pasa — en todos los sentidos de este hermoso verbo- por encima, por debajo, al costado y a través del poeta. Mientras el poeta se imagine dueño y señor de la palabra, incluso premiado y adorado, reconocido y laureado, o por ello mismo, será el peor de todos. No sé qué habrá movido a Bojórquez a escoger esos poemas, que desde muchos puntos de vista son realmente pésimos, aunque algunos, por estrambóticas y personales razones, no nos lo parecerán, pero donde sí acertó fue en la desacralización de sus perpetradores, buenos, regulares, malos o impresentables. El último en valorar un poema es su firmante; su verdad (la del poema) lo ha eludido limpiamente. Quien dijo que es poema si pervive en él algún resto, brizna, aroma, esquirla, pelusa, astilla o eco de lo sagrado — no de lo divino, por favor-, me parece que está en lo justo. Miren si no estas cuatro límpidas y poco estilizadas líneas de un hombre que ha perdido todo, un hombre al que no le falta nada, un alienado, un ser esplendente en su desnudez humana:

\section{Espléndida aparición, el aire es más puro, \\ Claro está el bosque, ningún hombre}

\section{Camina por las calles, ya tan lejanas, y el silencio}

\section{Se hace majestuoso y todo rie $e^{149}$}

Cuando Hölderlin escribe esto, cuatro versos de uno de sus poemas al Invierno, ya hace tiempo que ha sido declarado loco incurable. Si no loco obsesivo, sí loco por agotamiento, por fatiga absoluta. Gente noble y sin pretensiones lo protege. Podía entrar en éxtasis ante una coma (jentrar en coma por una coma!), podía llorar ante la invención de una palabra sin significado. Sólo en la palabra se siente seguro, protegido, sólo en ella sabe que no habrá de sucederle ningún infortunio. El poema lo hace estar en estado de gracia, que es algo que ningún ser normal desearía. No es sensato, ni aconsejable. Ese estado no es propicio a Estado alguno. Cuando alguien, en los comentarios que suceden a la lista de los peores

149 Friedrich Hölderlin, Poemas de la locura, tr. T. Santoro y J. M. Álvarez, Hiperión, Madrid, 1999, p. 31. En alemán: Die prächtige Erscheinung ist, die Luft ist feiner, /Der Wald ist hell, es geht der Menschen keiner / Auf Strassen, die zu sebr entlegen sind, die / Stille machet Erhabenheit, wie dennoch alles lachet. 
poemas de mexicanos en producción, dice que no hay poema si no se detecta la presencia de lo sagrado, tiene toda la razón; el problema es que no se sabe qué y qué no es sagrado.

A Hölderlin, ya loco, o en ese estado o pasmo indeterminable en el que se introdujo una tercera parte de su vida, le irritaba todo lo desconocido, todo lo que se movía de lugar, todo lo nuevo y extraordinario; su palabra se apartaba para dar sitio a lo sagrado, no lo "decía", una experiencia lo suficientemente aterradora y extática, consciente y comprometedora como para además soportar la gratuidad absoluta que depara cada instante vivido. El poema es la experiencia de lo sagrado, no el anhelo de transcribir un símbolo heredado y sedicentemente salvífico como para darse un estilo o para ser reconocido y homenajeado o para demostrarse enfrente de todos — O de una selecta tribu de lectores privilegiados — una destreza y un ingenio y una habilidad y un talento y un dominio sobre el lenguaje que nadie en su sano juicio, nótese la malicia, podría permitirse pretender. También hay locuras que son efecto de un exceso de cordura, o, mejor dicho, que son resultado de una exacerbación de la lucidez.

De ello dependen los demás rasgos, que estoy de acuerdo en contemplar con la mayor atención; el humor, sobre todo, y enseguida la expresividad, la honestidad y la generosidad (esta última no la mencionó nadie pero yo la agrego para no quedarme con las ganas). Las vías para quitarse de en medio, como pedía John Cage, son, en cierto sentido, infinitas. Es lo que hace el poeta, es lo hace a un poeta. Es su honestidad y su gracia. Según relata su amigo Wilhelm Waiblinger, el único con quien finalmente podía hablar, Hölderlin escribía a su madre como un niño que ha olvidado cómo escribir, es decir, cómo recordar, es decir, es decir, cómo decir, es decir, cómo pensar. "Aun cuando encierran belleza, frescura, claridad e incluso hay en ellos soberbios momentos de alto vuelo", ponderaba el amigo Wilhelm, "se encuentran, sin embargo, abismos que parecen manchas sombrías sobre una superficie de agua mansa y soleada"150. La expresión "sin embargo" delata que el amigo no era lo que se dice un poeta.

El poeta siempre tiene diecisiete años, como en la canción de Violeta Parra. El poeta entiende a los humanos a condición de volverse extraño a ellos. Pero puede ir y volver. El poeta es incapaz de sujetarse a una cadena de silogismos, de ideas, de representaciones: está desatado del mundo, que sólo existe para asegurar raciones mínimas de alimentos a cambio de no poder caminar libremente por bosques y praderas, por senderos sin nombre ni dirección ni código postal. Pero puede escribir cartas, aunque, para honrar a Rilke, nunca de amor. El poeta no transige, no negocia, no calcula, no abstrae, no se adapta ni se acomoda. Aunque conserva el poder de a veces cobrar un cheque o sufragar algún pagaré. El poeta sabe que el mundo y su funcionamiento son producto de una memoria que avasalla — y apaga — la incandescencia de las cosas que realmente ocurren. Aprende a olvidar. El poeta simple y llanamente no pertenece al mundo, porque el mundo es profano, prosaico y groseramente prosopopéyico. Pero confía devotamente en sus instintos.

$150 \quad$ Ibíd., p. 12. 
Al poeta lo hace y deshace el poema, que es el lugar donde podrían ocurrir — pero igualmente no- estas magníficas desgracias.

\section{II}

"Lo sagrado es el rastro de los dioses huidos". Son palabras de Heidegger, proferidas en dirección a Hölderlin. "Por eso es por lo que el poeta dice lo sagrado en la noche del mundo"151. "La noche del mundo" no es, ni lejanamente, una imagen poética. ¿Lo es "el rastro de los dioses huidos”? Que los dioses han huido es un hecho, un hecho "histórico"; de imagen poética no tiene nada (o sólo un poco). El filósofo parte en realidad de un diagnóstico del tiempo vivido —un diagnóstico dictado o formulado, eso sí, por el poeta-, que es el de la desdivinización (no, ojo, el ateísmo) y la profanación generalizada, y se esfuerza por captar la esencia de lo poético en estas expresiones. Si no hay dioses, si lo divino se aleja y se pierde, entonces el poema se verá en la necesidad de "decir lo sagrado", porque, en su huida, los dioses han dejado al mundo en la oscuridad; y sólo en esa ausencia de luz — - en la desaparición de su imagen, en la pérdida de su potencia - refulge lo sagrado. Sólo hay posibilidad de percibirlo en la fuga de los dioses y en la muerte de Dios. En la noche del mundo es posible "decir" lo sagrado; bajo la luminosidad de Dios, o de algún dios, tal decir se presenta como impracticable; es, para emplear la efigie de Diógenes de Sínope, como deambular en pleno día con una lámpara de queroseno.

Lo sagrado no es lo divino; es su pérdida, su retirada, su muerte. Cuando eso ocurre, piensa Heidegger, lo humano se extiende por el mundo o, mejor dicho, extiende un manto — el velo sujeto/objeto - por encima del ser, ocultándoselo a sí mismo. Lo humano - la representación humana del mundo, y sus efectoscubre finalmente la tierra en toda su amplitud, sustituye a lo real, se sobreimpone al ser, lo inviste todo, y el resultado es la pérdida no sólo de lo divino, sino también de lo sagrado, su "huella". Son modalidades del "olvido del ser", tema que - se sabe- moviliza toda la filosofía del mago de la Selva Negra. La luminosidad de lo divino es su carácter orientador: es una "señal", una “indicación". Le otorga al mortal un rumbo. No le "dice" nada, sólo es una indicación, un signo que por un momento hace pensar en un código desconocido. Quizá no, quizá sólo indica una salida, una ruptura, una rasgadura del orden humano.

Lo poético no es un sucedáneo de lo divino. No es una especie de premio de consolación ante la fuga de los dioses. Lo poético no está ahí, a disposición de los humanos, para bien y para mal, como una suerte de mito artificial. ¿En qué sentido es un testimonio necesario para no digamos la filosofía, sino para un pensamiento lúcido? La filosofía tiene su historia, la filosofía — tanto como la poesía- es humana; ¿qué saben ellas de los dioses, y de su desaparición? ¿Con quién establecer un diálogo, si ellos ya no escuchan? Un pensador como Heidegger, que es filósofo un poco por accidente y un poco a regañadientes, y por lo mismo mejor filósofo que el que más, adivina que con lo poético se abre la posibilidad de un diálogo no

151 Martin Heidegger, "¿Y para qué poetas?”, Caminos de bosque, tr. H. Cortés y A. Leyte, Alianza, Madrid, 1996 , p. 244 
de un sujeto con otro sujeto - de un interlocutor con otro interlocutor- ni de un sujeto con un mundo de objetos —el diálogo de las parsimonias científicas-, sino de lo otro de cada sujeto con lo otro del mundo. Tal es el "territorio" de la poesía.

¿Qué clase de diálogo podría ser ese? Quién sabe, acaso eso sólo las Musas podrían hacerlo presentir. ¿Las Musas? ¿No son ellas, por ventura, piedra angular de un "mito artificial”? ¿Habría mitos "naturales”? La antropología afirma, entretanto, sin llegar aún a la altura del mito, que hay símbolos naturales ${ }^{152}$. La londinense Mary Douglas, discípula de Victor Turner, haciendo pie en la gran tradición sociológica francesa, la de Durkheim y Mauss, se arriesga a decir que existen símbolos, si no enteramente naturales, sí "fundamentales", o universales, gracias a los cuales la naturaleza puede ser "leída"; esos símbolos son una proyección de la estructura social, humana, en todo aquello que en absoluto podría calificarse de humano. Hay una lectura fisiológica del cosmos, y enseguida una interpretación sociológica. La primera ha sido minuciosamente descrita en Pureza y peligro. Un análisis de los conceptos de contaminación y tabú, de 1966. Lo sagrado es, para la antropología, un asunto de desechos, de residuos no reciclables. El cuerpo (humano) pierde o se desembaraza de grandes fragmentos de sí, y de representaciones corporales concretas, y el aprender a ponerlos en su lugar despierta sentimientos ambiguos pero sumamente intensos. Douglas destaca un vínculo entre el asco y la divinidad que resulta cómico y al mismo tiempo revelador: "De acuerdo con la norma distanciadora con respecto al origen fisiológico (o, dicho con otras palabras, de acuerdo con la norma de pureza), cuanto mayor es la presión social, mayor es la tendencia a expresar la conformidad social por medio del control físico. Las funciones del cuerpo humano se ignoran y se delegan más cuanto mayor es la presión que ejerce el sistema. El modo de revestir de dignidad un acontecimiento social consiste en ocultar los procesos orgánicos. La distancia social se expresa en términos de distanciamiento de los orígenes fisiológicos, y viceversa"153. Es literalmente impensable un Dios que orine, que defeque, que escupa un gargajo, que se exprima un barro o se quite una legaña, que — horror al crimen! — se masturbe. Imaginarlo profiriendo improperios es igualmente chocante. ¿Un Dios diabético, hepático, o espástico o gastrítico? Tema de memes, nada más.

Impensable o no, es una posibilidad latente en el cristianismo, la — paradójica, aberrante, perversa, eficaz, recurrente- religión de un Absoluto que por amor — sentimiento ambiguo_ - habita una carne débil, exultante, deprimente, putrescible, mortal. Ni la filosofía ni el "pensamiento lúcido" podrían desentenderse de esto, por más absurdo, tonto o repulsivo que sea. La verdad, desde fuera, no deja de ser interesante la figura de un Dios que se deja matar de la manera más infamante y se hace resucitar tres días después (¿por qué tres y no cinco, o un minuto, o toda la vida?) para no morir del todo en vano... Quién sabe qué hubiera dicho Heidegger de no haber prosperado en un clima cristiano; iquién sabe cómo sería la poesía — la palabra de lo sagrado — en otro medio! Si lo divino se mide por su distancia a estas innoblezas y asquerosidades, a estas ridiculeces y faltas de gusto, ¿cómo comenzar a entender en serio a la aventura cristiana? Nietzsche anduvo

152 Cfr. Mary Douglas, Simbolos naturales. Exploraciones en cosmología, tr. C. Criado, Alianza, Madrid, 1988.

153 Ibíd., p. 9. 
desde luego muy cerca de hacerlo. Los dioses griegos se ríen, se excitan, se enfurecen, se disfrazan, se ofenden, se burlan, se regocijan: son entrañables - y odiosos por la misma razón. Pues bien, ellos se han retirado, dejándonos en reemplazo - aunque tenga sus momentos lúcidos - un Dios colérico, vengativo, arbitrario, rencoroso, omnipotente - e histérico. Y bien, también Ese, bendito sea el cielo, se ha retirado. Lo sagrado que "dice" la palabra poética es la senda, el camino de bosque, la veredita desde la cual se adivina que los dioses — divertidos o seriosnos han abandonado a nuestra (mala) suerte. Sagrada es la saudade provocada por su desdén, por su posible enojo. No hemos estado a la altura de ninguno de ellos. Menos del Más Alto.

En esas sendas perdidas (Holzwege) lo poético tiene lugar. Sólo en ellas. Lo poético está in media res; en medio de las cosas, entre las cosas. No arriba, no abajo, no adentro, no afuera: entre las cosas. Ha de ser como el alma. O el espíritu. Pero no, estas nociones se encuentran erróneamente desplazadas. El alma está adentro del sujeto, y el espíritu está afuera. Lo sagrado está entre, es un espacio que nada ni nadie rellena. Sagrado es el nombre del límite: del mundo, del lenguaje, del yo, del nosotros, de Dios, de cualquier abstracción o valor. Límite de lo representable, límite de lo humano. "Los tiempos", acota el filósofo, "no son sólo de penuria por el hecho de que haya muerto Dios, sino porque los mortales ni siquiera conocen bien su propia mortalidad ni están capacitados para ello. Los mortales todavía no son dueños de su esencia. La muerte se refugia en lo enigmático"154. No tenemos símbolos para la muerte. Representaciones, muchas. Todas, falsas. No las hay para la muerte porque tampoco las hay para la vida. Ambas parecerían ser demasiado grandes, heterogéneas al concepto y a la representación. Es el sentido de que sean "enigmas".

Lo poético es enigmático en ese mismo sentido: los poemas de verdad no dicen nada, o, por decirlo en tono budista, dicen la nada. Dicen no "la nada" en general, en su abstracción, que es lo más fácil, sino en su concreción hasta material: la nada que hay entre las cosas del mundo y entre mis propias representaciones, entre la representación de mi deseo y el deseo real. La nada que hay entre mi cuerpo y el cuerpo del otro (o de la otra, o las otras, si Dios es servido). No es, en el fondo, algo nuevo. Si la especie humana se ha enfrentado a cosas difíciles, el espacio y el tiempo son de las principales. Hay algo que no termina de serlo, ¿habría misterio más insistente, más desasosegante? El abismo, para el filósofo, siguiendo al poeta, no es la muerte, sino el sufrimiento... y el amor. Algo que ocurre entre:

No se reconocen los sufrimientos,

no se aprende el amor,

y eso que en la muerte nos aleja,

no se desvela.

Sólo el canto sobre la tierra

consagra y celebra ${ }^{155}$

154 Heidegger, op. cit., p. 246.

155 Rainer Maria Rilke, Sonetos a Orfeo, $1^{\mathrm{a}}$. parte, XIX 
"Eso que en la muerte nos aleja..." No la muerte, sino algo que hay en ella, una distancia menos aterradora que infranqueable. No el fin, sino el mientras. En esa distancia sin medida se da el canto de la poesía. Es un espacio sin coordenadas, sin norte y sur, sin colores, sin orillas ni embalses. Ni el aquí-y-ahora de los modernos, ni la eternidad antigua. El espacio de la poesía, para el pensador, es el de la muerte de Dios. No del fin de la creencia en Dios, que es un asunto de opinión pública (o privada), sino de la muerte de lo Representable. La poesía canta en ese abismo, que por lo mismo no puede representarse ni siquiera como un abismo; ni el "desierto de lo real" de Lacan o Zizek y ni siquiera como el lugar sin límites de José Donoso. Lo sagrado es ese hiatus que separa lo irrepresentable de la imagen (incluso sónica o fónica). Da nombre a la distancia infranqueable entre nuestros sentidos; por más próximos que se encuentren, ni hablar es ver, ni escuchar es tocar, ni oler es gustar. Los sentidos no están "de acuerdo" en nada, no necesitan estarlo. Los sentidos son, y ningún pensamiento filosófico les ha hecho justicia en semejante irresponsabilidad. Lo poético es aquello que canta en esos pequeños o inmensos abismos entre sentido y sentido, entre un sentido y el sentido.

El canto es eso, y no la rima o la métrica o la melodía o la metáfora o la "imagen poética" o la manía de romper una frase donde suene mejor y continuar así rompiéndolas y cosiéndolas hasta el infinito. El canto arriesga la palabra allí donde —ese "dónde" es un decir_— "actúa la gravedad de las fuerzas puras", como dice Rilke. El poeta y el pensador se mantienen atentos no a la naturaleza - no parece que la poesía sea del todo natural, pero tampoco es un artificio como los demás_-, sino a su abandono. Rilke afirma que "la naturaleza abandona a los seres al riesgo de su oscuro deseo", sin darle prevalencia a ninguno de ellos. Los seres — no sólo nosotros - tienen un oscuro deseo. Quiero conectar esto con la idea de clinamen de Lucrecio. Es muy próxima a la idea de deriva en psicoanálisis. ¿Mientan una especie de libertad en la naturaleza? El clinamen es una desviación imperceptible e irracional de los cuerpos, una especie de desobediencia a la ley a la cual no se le puede ajustar causalidad ni finalidad alguna. No admite ni por qué ni para qué. La naturaleza no es un reino de leyes implacables, sino un ámbito donde todo, en su regularidad y repetición, en su orden básico, es absolutamente excepcional. Sólo merced al clinamen es practicable una explicación física, por más que esta teoría haya sido relegada históricamente como un absurdo manifiesto. Es lo que explica el majestuoso movimiento del suave mari magno: "el clinamen", observa Michel Serres en su libro sobre Lucrecio, "es la condición mínima que podemos concebir para la formación primigenia de una turbulencia"156. Algo similar puede decirse de las derivas —en alemán: Triebe — sobre las que trabajan y navegan Freud y el psicoanálisis.

Pues bien, el poema — más que el poeta— se deja leer como esa "desviación imperceptible e irracional" sin cuyo riesgo ningún orden es imaginable. Es la palabra que navega en el corazón oscuro de lo excepcional — sin presumir, sin jactarse de ello: con soltura y con inocencia. "La gravedad de las fuerzas puras", escribe Heidegger, "el centro inaudito, la pura percepción, la completa percep-

156 Michel Serres, El nacimiento de la física en el texto de Lucrecio. Caudales y turbulencias, tr. J. L. Pardo, Pre-textos, Valencia, 1994, p. 22. 
ción, la plena naturaleza, la vida, el riesgo, son lo mismo"157. A todo esto, Rilke le otorga por su parte el nombre de lo abierto. Por el poema accede lo abierto a nuestra conciencia, no nuestra conciencia a su exterioridad; la iniciativa no es de la conciencia, sino de lo abierto, en un movimiento que revierte los papeles del yo, del nosotros (super-yo) y del Ello: el poema es la presencia consciente —y lúcidade lo inconsciente, una presencia que modifica, amplifica, agudiza, intensifica y hace destellar a la conciencia. ¿Cómo logra hacerlo? Destrabándola de su nexo de obligatoriedad con el mundo; suspendiendo o eliminando la conciencia moral a la que estamos normalmente sujetos. A diferencia de nuestro vínculo conceptual con las cosas, que opera mediante recorte y captura, que "caza" los objetos para después desplumarlos, destazarlos y servirlos en caldo o a la plancha, el poema apunta a una relación de desapropiación o desobjetivación que alcanza hasta la propia subjetividad. El poema es una relación abierta con lo abierto, un decir que deja ser a las cosas en lo que son en sí y para sí mismas, un decir que —a riesgo de perderlos — abandona a los seres "al riesgo de su oscuro deseo".

Con esto último, y para terminar, confieso mi toma de partido por el poeta en su diferencia con el filósofo; éste se conforma con describir el abismo al que el poeta se ha arrojado sin pensarlo demasiado. Describe el riesgo sin correrlo. Si lo corriera, sería poeta, y no filósofo. Y, a la verdad, no cualquiera.

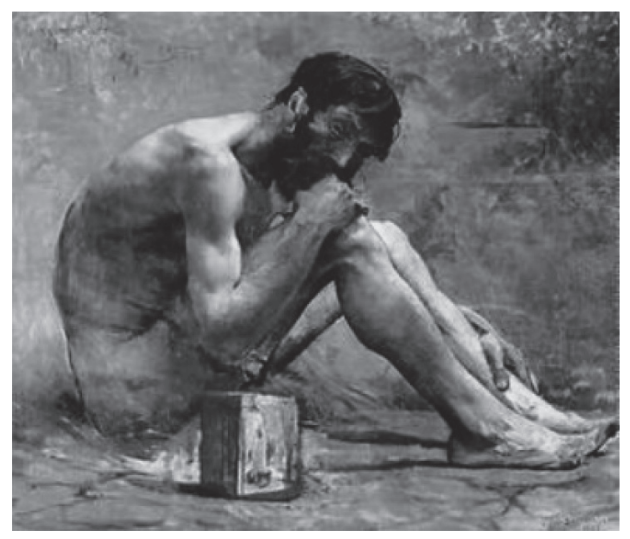

